Part of Journal of Research of the National Bureau of Standards, Volume 30, May 1943

\title{
DISSOCIATION CONSTANTS AND pH-TITRATION CURVES AT CONSTANT IONIC STRENGTH FROM ELECTRO- METRIC TITRATIONS IN CELLS WITHOUT LIQUID JUNCTION: TITRATIONS OF FORMIC ACID AND ACETIC ACID
}

\author{
By Roger G. Bates, Gerda L. Siegel, and S. F. Acree
}

\section{ABSTRACT}

An improved method for obtaining the titration curves of monobasic acids is outlined. The sample, 0.005 mole of the sodium salt of the weak acid, is dissolver in $100 \mathrm{ml}$ of a $0.05-\mathrm{m}$ solution of sodium chloride and titrated electrometrically with an acid-salt mixture in a hydrogen-silver-chloride cell without liquid junction. The acid-salt mixture has the composition: nitric acid, $0.1 \mathrm{~m}$; potassium nitrate, $0.05 \mathrm{~m}$; sodium chloride, $0.05 \mathrm{~m}$. The titration therefore is performed in a medium of constant chloride concentration and of practically unchanging ionic strength $(\mu=0.1)$. The calculations of $\mathrm{pH}$ values and of dissociation constants from the emf values are outlined. The titration curves and dissociation constants of formic acid and of acetic acid at $25^{\circ} \mathrm{C}$ were obtained by this method. The $\mathrm{p} K$ values (negative logarithms of the dissociation constants) were found to be 3.742 and 4.754 , respectively.

\section{CONTENTS}

Page

II. Discussion of the titration method

1. Titration curves at constant ionic strength from cells without

liquid junction

2. Dissociation constants

III. Dissociation constants of formic and acetic acids at $25^{\circ} \mathrm{C}_{\ldots}$

1. Materials _...

2. Procedure

3. Results and calculations

IV. References

\section{INTRODUCTION}

It has long been recognized that measurement of the changes of $\mathrm{pH}$ during the neutralization of a weak acid with alkali can be employed to obtain an accurate value for the strength of the acid or its dissociation constant. In electrometric titration, the $\mathrm{pH}$ values are measured at successive steps in the titration by means of the changing potentials of suitable electrodes immersed in the solution. According to usual practice, successive portions of a solution of strong alkali are added to a sample of pure acid, and the $\mathrm{pH}$ values of the several mixtures are determined. The titration is performed in a cell that contains a hydrogen, glass, or quinhydrone electrode. The cell 
system is completed by a reference half-cell (calomel, silver chloride, etc.) whose electrolyte is brought into liquid-liquid contact with the acid solution in the titration vessel.

The $\mathrm{pH}$ values that are derived from the emf measurements of such a cell often involve considerable uncertainty, and in unfavorable cases they may be in error by more than $0.05 \mathrm{pH}$ unit $[1,2] .{ }^{1}$ The principal reason for this difficulty is neglect of the contribution of the potential at the liquid junction or in the application of improper or inadequate corrections for it. Such corrections are laborious and unsatisfactory and require a knowledge, often unavailable, of the mobilities and activities of the ions of which the solutions are composed. For accurate work, liquid junctions are to be avoided whenever possible. For approximate work, however, cells with a liquid junction are often useful.

The second limitation to the accuracy of these titrations has its origin in the changing concentration of ionized solutes in the cell during the titration. A solution of the weak acid has a low ionic strength, whereas its salt is a strong electrolyte. It is well known that there is an infinity of titration curves for a particular weak acid, each one corresponding to a different ionic strength. Although the effect of the change in ionic strength on the $\mathrm{pH}$ values measured during the course of the titration may be small, the titration curve will be distorted unless the total ionic concentration is held at a constant value while the series of experiments is being performed. As a rapid means of obtaining dissociation constants of weak electrolytes, however, the titration procedure has much to recommend it. It has seemed worth-while, therefore, to attempt to improve its accuracy.

It is the purpose of this paper to present a method for obtaining $\mathrm{pH}$-titration data and dissociation constants for weak monobasic acids by means of electrometric titrations in a hydrogen-silverchloride cell without liquid junction. An alkali-metal salt of the weak acid in sodium chloride solution is titrated with nitric acid solution to which have been added sodium chloride and potassium nitrate in amounts sufficient to maintain unchanging chloride concentration and constant ionic strength as the salt is changed into weak acid. The method has been applied to the determination of the dissociation constants of formic acid and of acetic acid. Comparison with the best data in the literature indicates that $\mathrm{p} K$ values accurate to 0.01 unit were obtained.

\section{DISCUSSION OF THE TITRATION METHOD}

When an electrometric titration is performed, data for the entire titration curve are ordinarily obtained within 3 or 4 hours. Unusual precautions must therefore be exercised to insure rapidity of equilibrium after the addition of each increment of acid or alkali. The potential of the hydrogen electrode adjusts itself rapidly, in the absence of oxygen, to changing $\mathrm{pH}$. The silver chloride electrode, however, is slow to come to equilibrium when the chloride-ion concentration is changed, for equalization of the chloride-ion concentration in the porous electrode and in the solution must take place by

\footnotetext{
1 Figures in brackets indicate the literature references at the end of this paper.
} 
diffusion. When constant chloride-ion concentration is maintained, however, equilibrium is rapid, and the emf values may be obtained readily. The calculation of $\mathrm{pH}$ values and of the dissociation constant of the weak acid from the experimental data are described in detail in the following sections.

\section{TITRATION CURVES AT CONSTANT IONIC STRENGTH FROM CELLS WITHOUT LIQUID JUNCTION}

The hydrogen-silver-chloride cell without liquid junction may be represented by the following arrangement:

$$
\mathrm{Pt}\left|\mathrm{H}_{2}\right| \mathrm{H}^{+}, \mathrm{Cl}^{-}|\mathrm{AgCl}| \mathrm{Ag} \text {, }
$$

where $\mathrm{H}^{+}$and $\mathrm{Cl}^{-}$represent the components of the cell electrolyte to which the cell is reversible. The emf of the cell at a centigrade temperature, $t$, is related to its standard potential, $E^{\circ}$, and to the activities, $\boldsymbol{a}$, of these two ions by the equation

$$
\frac{\left(E-E^{\circ}\right) \boldsymbol{F}}{2.3026 R T}=-\log \left(\boldsymbol{a}_{\mathrm{H}} a_{\mathrm{Cl}}\right)=\left(E-E^{\circ}\right) / k,
$$

or

$$
-\log \boldsymbol{a}_{\mathrm{H}}=\left(E-E^{\circ}\right) / k+\log \boldsymbol{a}_{\mathrm{Cl}},
$$

where $R$ is the gas constant (8.3127 Int. j. $\operatorname{deg}^{-1}$ mole $\left.^{-1}[3]\right), T$ is the absolute temperature $(t+273.16)$ [4], $\boldsymbol{N}$ is the faraday (96,500 Int. coulombs [4]), and $k$ is written for $2.3026 R T / F$.

The problem of determining $\mathrm{pH}\left(=-\log \boldsymbol{a}_{\mathrm{H}}\right)$ from emf measurements of cells of type 1 resolves itself into estimation of the activity coefficient, $f_{i}$, of chloride ion. It is noteworthy that all methods of $\mathrm{pH}$ determination must deal with this theoretical difficulty in one form or another ${ }^{2}$. The least ambiguous solution is possibly that which assumes a simple relation among the activity coefficients of all the ions of which the mixture is composed. Thus the activity coefficient of chloride ion (and of other singly charged ions) is considered to be equal to the mean activity coefficient of hydrochloric acid in the mixture.

The activity coefficient of any ion species, $i$, in the mixture may be represented by the Hückel equation [5],

$$
-\log f_{i}=\frac{A z_{1}^{2} \sqrt{\mu}}{1+B a_{i} \sqrt{\mu}}-\beta \mu
$$

where $\mu$ is the ionic strength $\left(1 / 2 \Sigma m_{i} z_{1}^{2}\right), z_{i}$ is the valence of the ion, the molality of which is $m_{i}$, and $A$ and $B$ are constants that vary only with the temperature and dielectric constant of the solution. The values of $A$ and $B$ at $20^{\circ}, 25^{\circ}$, and $30^{\circ} \mathrm{C}$ [6] are given in table 1 , together with $E^{\circ}$ and $k$.

When the proper values of parameters $a_{i}$ and $\beta$ are used, eq 3 describes the change of the activity coefficient of hydrochloric acid with ionic strength of the mixture. The parameter $a_{i}$ has dimensions of length and is often called the "ion size." Only singly charged ions are involved in the titration of monobasic acids by the method outlined here. In this paper, therefore, $f_{i}$ represents the activity coefficient of a univalent ion.

\footnotetext{
${ }^{2}$ A critical comparison of errors involved in determining $\mathrm{pH}$ from cells with liçuid junction and from cells without liquid junction has been made by Hamer [2].
} 
TABLE 1.-Numerical values of $E^{\circ}, k, A$, and $B$ at $20^{\circ}, 25^{\circ}$, and $30^{\circ} \mathrm{C}$

\begin{tabular}{|c|c|c|c|c|}
\hline$t$ & $E^{\circ}$ & $k$ & $A$ & $B$ \\
\hline $\begin{array}{l}{ }^{\circ} \mathrm{C} \\
20 \\
25 \\
30\end{array}$ & $\begin{array}{r}\text { Int.v } \\
0.22550 \\
.22238 \\
.21911\end{array}$ & $\begin{array}{c}\text { Int. } v \\
0.05815 \\
.05914 \\
.06013\end{array}$ & $\begin{array}{r}0.505 \\
.510 \\
.515\end{array}$ & $\begin{array}{r}0.329 \\
.330 \\
.331\end{array}$ \\
\hline
\end{tabular}

Since $\boldsymbol{a}_{C 1}=f_{C 1} m_{C 1}$, where $m$ represents molality, eq 2 and 3 can be combined, as shown by Hamer and Acree [7], to give an expression which can be used for the computation of $\mathrm{pH}$ values from emf measusements. The term $\beta \mu$ in eq 3 is a secondary correction to the $\mathrm{pH}$ at low ionic strengths ${ }^{3}$ but is very important at high concentrations. It is usually found to contribute less than 0.01 unit to the $\mathrm{pH}$ value at an ionic strength of 0.1 . For approximate $\mathrm{pH}$ determination, $\beta \mu$ may safely be neglected. When both $m_{C 1}$ and $\mu$ are the same for a series of emf measurements, eq 2 becomes simply

$$
\mathrm{pH}=\left(E-E^{\circ \prime}\right) / k,
$$

where $E^{\circ \prime}$ is defined by

$$
E^{\circ \prime}=E^{\circ}-k \log m_{\mathrm{Cl}}-k \log f_{i} .
$$

These conditions of constant chloride molality and of constant ionic strength over the entire range of the titration curve ${ }^{4}$ were achieved by the proper choice of concentrations for the solution of the sodium salt to be titrated and for the components of the acid mixture with which the titration was performed. The sample, 0.005 mole of the sodium salt of the weak monobasic acid was dissolved in $100 \mathrm{ml}$ of $0.05-m$ sodium chloride solution. The acid mixture was composed of nitric acid at a molality of approximately 0.1 , together with potassium nitrate and sodium chloride, each at a molality of 0.05 .

In two experiments, the sample was dissolved in $200 \mathrm{ml}$ of $0.05-\mathrm{m}$ sodium chloride solution. The ionic strength in these two titrations was therefore about 0.077 instead of 0.1 and changed about 6 percent during the titration. Another titrating solution which contained somewhat less potassium nitrate could have been used to offset this change in ionic strength.

\section{DISSOCIATION CONSTANTS}

The negative logarithm of the apparent dissociation constant of the acid, $\mathrm{p} K^{\prime}$, at the ionic strength of the experimental solutions, is given by

$$
\mathrm{p} K^{\prime}=\left(E-E^{\circ}\right) / k+\log m_{\mathrm{Cl}}-\log \left(M_{\mathrm{A}} / M_{\mathrm{HA}}\right),
$$

which, combined with eq 5 , gives

$$
\mathrm{p} K^{\prime}=\left(E-E^{\circ \prime}\right) / k-\log \left(M_{\mathrm{A}} / M_{\mathrm{HA}}\right)-\log f_{i}
$$

\footnotetext{
${ }^{3}$ If $\beta$ has a value of $0.1, \beta \mu$ is about 9 percent of $-\log f_{i}$ at an ionic strength of 0.1 , and only 0.6 percent at an ionic strength of 0.001 .

4 The principle of constant anion or cation concentration in the titration of salts of weak acids or bases in cells with liquid junction was used by Meacham, Hopfield, and Acree [8] and by Mellon, Acree, Avery, and Slagle [9].
} 
where $M_{\mathrm{A}} / M_{\mathrm{HA}}$ represents the mole ratio of acid anion to undissociated acid. This ratio is obtained in the usual way by correcting for the dissociation of the weak acid. The correction for dissociation contributites only 4 percent ( $0.002 \mathrm{pH}$ unit) to the ionic strength for the most acid formate mixture and accordingly need not cause serious concern in a determination of this type. Here again, a decrease in the amount of potassium nitrate used in the titrating acid would compensate for this small change in ionic strength.

Since the values of the activity coefficients of chloride ion and of the acid anion in the mixtures may not actually be identical (as assumed in eq 6), $\mathrm{p} K^{\prime}$ differs somevhat from the negative logarithm of the true dissociation constant, $\mathrm{p} K^{5}$. The true $\mathrm{p} K$ can be obtained, however, from $\mathrm{p} K^{\prime}$ values at two or more ionic strengths by extrapolation to the limit, $\mu=0$, where the two activity coefficients are both unity.

The change of apparent dissociation constant with ionic strength is small for most monobasic acids. For formic acid, $\mathrm{p} K^{\prime}$ at an ionic strength of 0.1 is 0.009 unit higher than the value at zero concentration [10], whereas the measurements of Harned and Ehlers [11] indicate that the corresponding increase in $\mathrm{p} K^{\prime}$ for acetic acid is even smaller, or about 0.005 unit. The observed difference between $\mathrm{p} K^{\prime}$ at the two ionic strengths (0.1 and 0.077$)$ used here should accordingly be about 0.002 unit, or less than the error of the measurement. An extrapolation was therefore not attempted.

The choice of $a_{i}$ (eq 3 ) has no bearing upon the value of $\mathrm{p} K$ obtained, for $f_{1}$ does not influence the values of $\mathrm{p} K^{\prime}$ derived from eq 6 and 7 . The accuracy of the $\mathrm{pH}$ values (eq 4), however, is limited by the uncertainty in $\log f_{i}$ and, consequently, in $E^{\circ \prime}$.

Although there is no known means of predicting the numerical values of the constants of the Hückel equation for a particular mixture, it is probable that an $a_{i}$ value between 3 and $5 \mathrm{~A}$ is required to represent the activity coefficient of hydrochloric acid in most solutions of uni-univalent salts. ${ }^{6}$ As a mean value, therefore, $4 \mathrm{~A}$ has been chosen for the computation of the $\mathrm{pH}$ values. The contribution of the activity coefficient to the $\mathrm{pH}$ at an ionic strength of 0.1 is, then, assumed to be 0.114 unit. Had $3 \mathrm{~A}$ been used for $a_{i}$, the $\mathrm{pH}$ values would all have been lower by 0.009 unit, and the use of $5 \mathrm{~A}$ would have resulted in an increase of 0.008 unit over those values listed in tables 2 to 7 . An accuracy of \pm 0.01 unit can probably be ascribed to the $\mathrm{pH}$ values.

\footnotetext{
${ }^{3}$ As an alternate explanation of tre slope of tne plot of $\mathrm{p} K^{\prime}$ with respect to $\mu$, the activity coefficient of the
undissociated acid, assumed to be unity in eq 6 and 7 , can be considered to change, wnile the activity coefficients of chloride ion and of acid anion remain identical at all ionic strengths. Both assumptions lead to the same value of $\mathrm{p} K$.

${ }^{6}$ Values of $a_{i}$ between 3 and 5 A have also been found to be characteristic of mixtures which contain bivalent ions, A value of $3.8 \mathrm{~A}$ was found to give the best representation of the activity coefficient of hydrochloric acid in mixtures of primary phosphate, secondary phosphate, and sodium chloride at room temperature [12]. In sodium acid malonate-disodium malonate-sodium chloride buffers, $4.75 \mathrm{~A}$ gives the proper expression for the activity coefficient [6]. In unpublished measurements in this Bureau, W. J. Hamer has found the value of $3.76 \mathrm{~A}$ to apply both to mixtures of phthalic acid, potassium acid phthalate, and potassium chloride, and to mixtures of acid potassium phthalate, dipotassium phthalate, and potassium chloride. Unpublished work by the authors of this paper, however, showed that an $a_{i}$ value of $8 \mathrm{~A}$ was required to represent correctly the activity coefficient function in buffers of potassium $p$ phenolsulfonate, sodium hydroxide, and sodium chloride. In a study of two completely dissociated mixtures of uniunivalent electrolytes, W. J. Hamer and G. D. Pinching (unpublished work) have found 3.5 A to apply to hydrochloric acid-potassium $p$-phenolsulfonate solutions and to solutions which contain hy. drochloric acid and sodium 4-chlorophenol-2-sulfonate.
} 


\section{DISSOCIATION CONSTANTS OF FORMIC AND ACETIC ACIDS AT $25^{\circ} \mathrm{C}$}

\section{MATERIALS}

Sodium chloride and potassium nitrate that conformed with specifications of the American Chemical Society were recrystallized once before use. Sodium formate and sodium acetate of reagent grade were found to be sufficiently pure. Two samples of sodium formate were assayed by evaporating a mixture of the salt and sulfuric acid to dryness and weighing the residue. Both analyses gave 99.96 percent, calculated as sodium formate. Two samples of sodium acetate treated in the same way gave 99.89 percent and 99.92 percent. Three further analyses made by heating the salt with dilute sulfuric acid, distillation of the acetic acid, and titration with standard alkali, however, gave $100.27 \pm 0.08$ percent, calculated as sodium acetate. The presence of 0.1 percent of inert impurity in the sample of sodium salt results in an error of 0.001 unit in $\mathrm{p} \bar{K}^{\prime}$ at the midpoint of the titration; when the titration is 90 percent complete, the error in $\mathrm{p} K^{\prime}$ is 0.004 unit.

All of the salts were powdered and dried at $110^{\circ} \mathrm{C}$ before use. The sodium acetate was partially dehydrated over concentrated sulfuric acid at reduced pressure before it was subjected to elevated temperatures.

The stock solution of sodium chloride was prepared from weighed amounts of water and of the dry salt. The acid solution was prepared by dissolving sufficient colorless concentrated nitric acid in water to make a solution approximately $0.1 \mathrm{~m}$. Clean dry air had been bubbled through the nitric acid to remove oxides of nitrogen. The solution was weighed and a preliminary, rough determination of its acid content made. Enough sodium chloride and potassium nitrate were added to make the titrating solution $0.05 \mathrm{~m}$ with respect to each salt. Hydrogen was then passed through the solution to remove dissolved air. The acid solution was kept under hydrogen in storage flasks of Pyrex glass.

All rubber tubes or stoppers exposed to the nitric acid solution or vapor were coated lightly with paraffin, and the storage vessel was protected from light. Black paper that covers the flask or bottle completely is considered preferable to the use of a dark bottle for this purpose, since it facilitates inspection of the solution for the appearance of the yellow color which indicates decomposition of the nitric acid. If a yellow color should appear, hydrogen saturated with moisture should be bubbled through the solution for some time. The acid value should then be redetermined.

The acid titrating solution was standardized by weight titrations with a carbonate-free sodium hydroxide solution which, in turn, had been standardized against acid potassium phthalate, NBS Standard Sample 84a. The average deviation of the analyses was 0.03 percent.

The water thermostat, the potentiometric equipment, and the preparation of the hydrogen electrodes have been described in an earlier publication from this Bureau [12]. The silver-silver-chloride electrodes were of a semimicro type, designed to reduce the possibility of poisoning of the hydrogen electrodes by the deposition of silver upon the catalytic surfaces. Poisoning did not occur in any case. 
Loops of platinum wire about $6 \mathrm{~mm}$ in length, sealed into soft glass, served as bases for the electrodes. A coating of silver, approximately $16 \mathrm{mg}$ in weight, was formed on each loop by the thermal decomposition of silver oxide. The electrodes were chloridized in $1 M$ hydrochloric acid for 15 minutes with a current of $3 \mathrm{ma}$.

\section{PROCEDURE}

The titration"cell is a modification of a cell for titrations with liquid junction previously described by Burton, Hamer, and Acree [13].

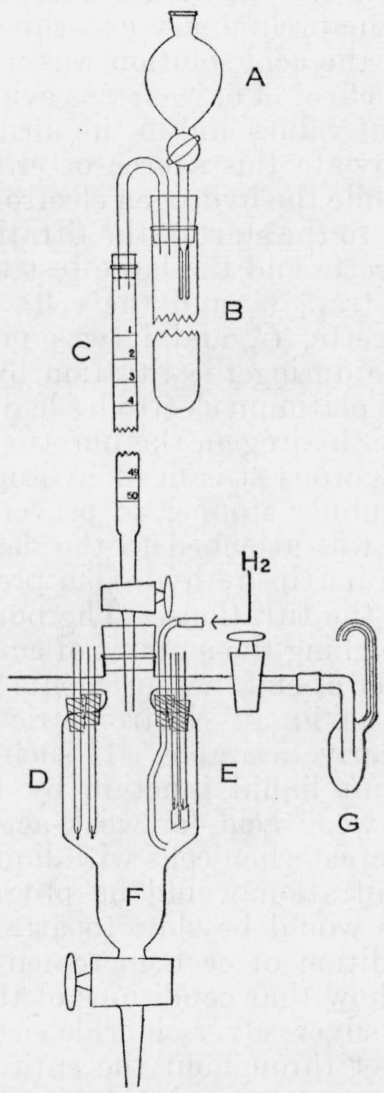

Figure 1.-Assembly of apparatus for electrometric titrations without liquid junction.

The arrangement of electrodes and burette in the cell is shown in figure 1.

The weighed sample of the sodium salt of the weak acid was introduced into the titration cell, $F$, and the sodium chloride solution was added from a calibrated pipette. The two platinized electrodes, $E$, were fixed in place by means of small rubber stoppers, and the hydrogen flow was started. The silver chloride electrodes, $D$, were usually placed in the cell just before the titration was begun - at the time when the burette was filled. Both the silver chloride electrodes and the hydrogen electrodes were usually freshly prepared for each series of experiments. The silver chloride electrodes were kept in 
0.05- $m$ sodium chloride solution until used, and the platinized foils were stored in distilled water.

The two silver chloride electrodes usually agreed in potential within $0.04 \mathrm{mv}$. In the poorly buffered solutions at the beginning of the titration, hydrogen electrodes ordinarily differed by 1 to $2 \mathrm{mv}$, but the emf difference dropped to 0.01 to $0.02 \mathrm{mv}$ as soon as $1 \mathrm{ml}$ of acid solution had been added.

In recognition of the deleterious effect of oxygen, both on hydrogen and on silver-silver-chloride electrodes, precautions were taken to exclude traces of air from the titration cell and from the acid-titrating solution. In some of the preliminary experiments, air was permitted to enter the burette as the acid solution was withdrawn. Before the end of the titration the effect of oxygen was evident in the slow attainment of equilibrium emf values and in the unsteadiness of the hydrogen electrodes. To obviate this source of error, the hydrogen that escaped from the cell while the hydrogen electrodes were being brought to equilibrium previous to the start of the titration was allowed to pass through the empty burette and the large test tube, $B$, by closing the stopcock between the trap, $G$, and the cell. In this way, air was removed from the burette, $C$, and it was prevented from gaining entrance to the burette during the titration by filling the funnel, $A$, with water. When the platinum electrodes had been allowed sufficient time for saturation with hydrogen, the burette was removed from the titration cell, and a vigorous stream of hydrogen was passed into $F$ and out through the rubber stopper to prevent entrance of air into the cell. The burette was attached to the flask containing the acid solution, filled through its tip by hydrogen pressure, and replaced in the rubber stopper for the titrations. The burette was calibrated at intervals of $5 \mathrm{ml}$ by weighing the amount of acid solution delivered.

Where a large number of emf measurements must be made without sacrifice of accuracy, as in an electrometric titration, rapidity of equilibrium is particularly desirable. If such a titration were performed in a cell without liquid junction by the addition of strong: alkali to a solution of weak acid (or weak-acid-chloride mixture) as has been the usual practice when cells with liquid junction were used, the chloride-ion concentration would be progressively lowered, and the reference electrode would be slow to attain its new equilibrium potential after the addition of each increment of titrating solution. These measurements show that conditions of thermodynamic equilibrium between a small silver-silver-chloride electrode and the solution may be successfully met throughout the entire titration if oxygen is excluded and if the temperature, ionic strength, and chloride concentration are held constant.

The initial emf measurements, made before any acid solution had been admitted to the cell, drifted upward at a rate of several tenths of a millivolt per minute. After about 2 percent of the salt had been titrated, however, the cell attained a constant emf within 1 to 2 minutes following the addition of an increment of acid. This emf value rarely changed more than $0.1 \mathrm{mv}$ when no more acid was added during the next 5 to 15 minutes. In one case, the cell was found to change $0.18 \mathrm{mv}$ (corresponding to $0.003 \mathrm{pH}$ unit) in 45 minutes. The entire titration usually required about 3 hours, when the acid was added at intervals of 10 minutes. If the titration is performed in an air bath or constant-temperature room, a longer time is required for 
thermal equilibrium to be attained, since the heat of neutralization is dissipated but slowly under these conditions.

If neither the sodium or potassium salt of the weak acid is available, a sample of the free acid can be used. The acid should be neutralized carefully with standard alkali and the necessary amounts of water and solid sodium chloride added before the start of the titration with nitric acid. The neutralization can be performed electrometrically in the titration cell. Perchloric acid and sodium perchlorate can be substituted for nitric acid and potassium nitrate as components of the titrating solution if desired.

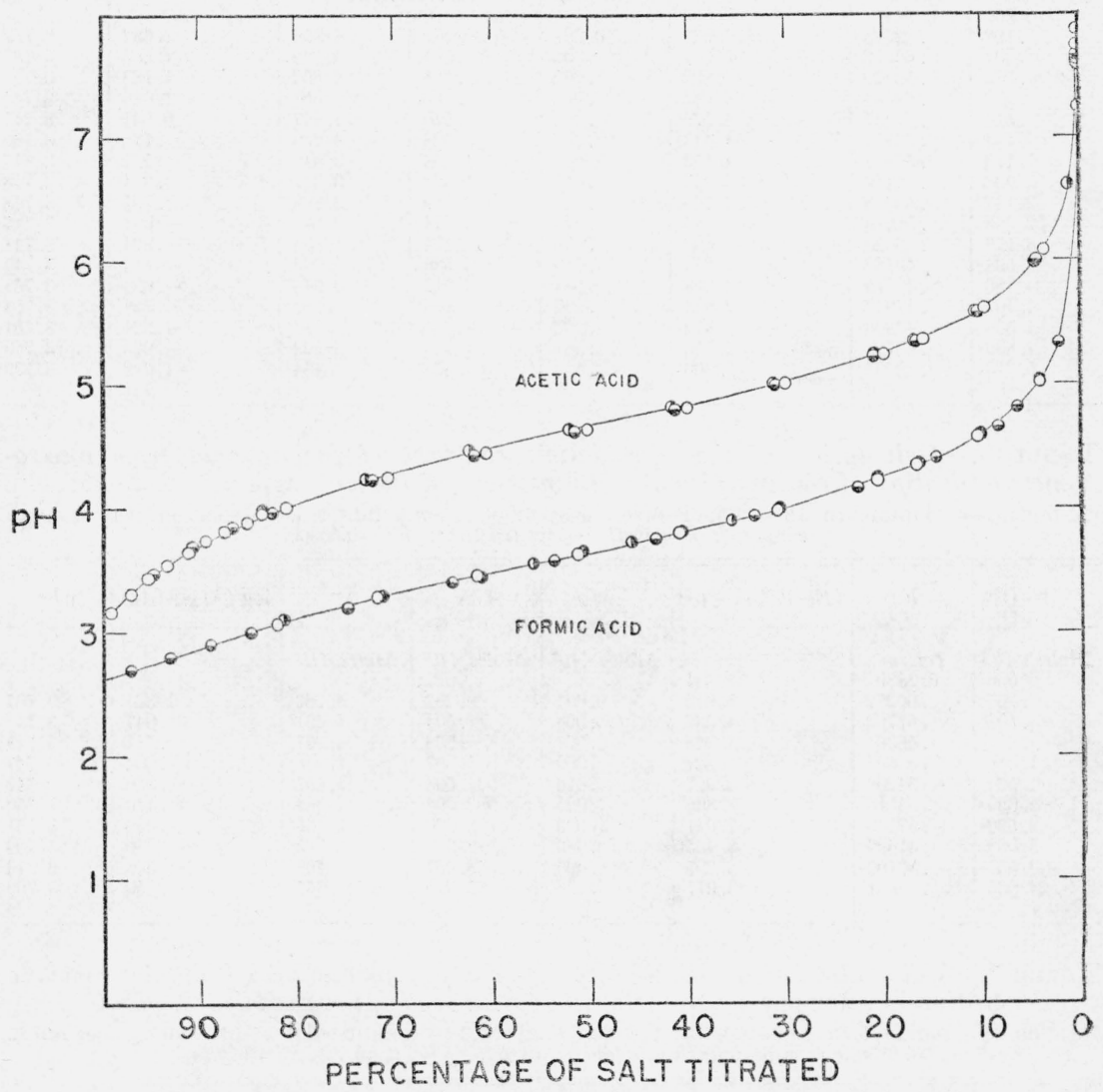

FIGURE 2.- $\mathrm{pH}$-titration curves for formic and acetic acids.

The data of six experiments are represented.

$\vartheta=$ experiments 1 and $5 ; \quad=$ experiments 2 and $4 ; 0=$ experiments 3 and 6 .

\section{RESULTS AND CALCULATIONS}

The results of three electrometric titrations of sodium formate and three of sodium acetate are summarized in tables 2 to 7 . The emf values have been corrected to a hydrogen pressure of $760 \mathrm{~mm}$. Experiment 1 was performed at $30^{\circ} \mathrm{C}$, and the other five were carried out at $25^{\circ} \mathrm{C}$ in the water thermostat. The $\mathrm{pH}$ values were computed from eq 4 , and $\mathrm{p} K^{\prime}$ was derived from eq 7 . Figure 2 is a plot of all the titration data for formic acid and acetic acid mixtures. The $\mathrm{pH}$ 
values of the formate solutions in experiment 1 at $30^{\circ} \mathrm{C}$ were so close to those at $25^{\circ} \mathrm{C}$ that a single curve has been drawn through the results of all three experiments.

TABLE 2.-Calculation of the dissociation constant of formic acid from electrometric titration of sodium formate with nitric acid reagent: experiment $1,30^{\circ} \mathrm{C}$

[Millimoles of sodium formate $=4.957$, dissolved in $100 \mathrm{ml}$ of $0.05-\mathrm{m}$ sodium chloride solution; ionic strength constant, $\left.\mu=0.0996 ;-\log f_{i}=0.115 ; E^{\circ \prime}=0.30425\right]$

\begin{tabular}{|c|c|c|c|c|c|c|c|}
\hline $\mathrm{HNO}_{3}$ & $E$ & $\left(E-E^{\circ \prime}\right) / k=\mathrm{pH}$ & $M_{\mathrm{H}}$ & HA & $A^{-}$ & $\log \left(M_{\mathrm{A}} / M_{\mathrm{HA}}\right)$ & $\mathrm{p} K^{\prime}$ \\
\hline $\begin{array}{r}\text { Moles } \times 10^{3} \\
0.000 \\
.102 \\
.207 \\
.307 \\
.409 \\
.514 \\
.714 \\
1.118 \\
1.638 \\
2.147 \\
2.658 \\
3.173 \\
3.698 \\
4.196 \\
4.402 \\
4.608 \\
4.809 \\
5.013\end{array}$ & $\begin{array}{c}\text { Int. } v \\
0.7643 \\
.62528 \\
.60532 \\
.59420 \\
.58585 \\
.57937 \\
.56958 \\
.55519 \\
.54157 \\
.53033 \\
.51983 \\
.50920 \\
.49753 \\
.48515 \\
.47947 \\
.47336 \\
.46723 \\
.46097\end{array}$ & $\begin{array}{l}7.650 \\
5.339 \\
5.007 \\
4.822 \\
4.683 \\
4.575 \\
4.413 \\
4.173 \\
3.947 \\
3.760 \\
3.585 \\
3.408 \\
3.214 \\
3.008 \\
2.914 \\
2.812 \\
2.710 \\
2.606\end{array}$ & $\begin{array}{c}\text { Moles } \times 10^{3} \\
0.001 \\
.002 \\
.002 \\
.003 \\
.004 \\
.006 \\
.010 \\
.018 \\
.028 \\
.044 \\
.069 \\
.110 \\
.184 \\
.232 \\
.297 \\
.381 \\
.490\end{array}$ & $\begin{array}{r}\text { Moles } \times 10^{3} \\
0.101 \\
.205 \\
.305 \\
.406 \\
.510 \\
.708 \\
1.108 \\
1.620 \\
2.119 \\
2.614 \\
3.104 \\
3.588 \\
4.012 \\
4.170 \\
4.311 \\
4.428 \\
4.523\end{array}$ & $\begin{array}{c}\text { Moles } \times 10^{3} \\
4.856 \\
4.752 \\
4.652 \\
4.551 \\
4.447 \\
4.249 \\
3.849 \\
3.337 \\
2.838 \\
2.343 \\
1.853 \\
1.369 \\
0.945 \\
.787 \\
.646 \\
.529 \\
.434\end{array}$ & $\begin{array}{r}1.682 \\
1.365 \\
1.183 \\
1.050 \\
0.941 \\
.778 \\
.541 \\
.314 \\
.127 \\
-.047 \\
-.224 \\
-.418 \\
-.628 \\
-.724 \\
-.824 \\
-.923 \\
-1.018\end{array}$ & $\begin{array}{l}\text { 3. } 772 \\
\text { 3. } 757 \\
\text { 3. } 754 \\
\text { 3. } 748 \\
\text { 3. } 749 \\
\text { 3. } 750 \\
\text { 3. } 747 \\
\text { 3. } 748 \\
\text { 3. } 748 \\
\text { 3. } 747 \\
\text { 3. } 747 \\
\text { 3. } 747 \\
\text { 3. } 751 \\
\text { 3. } 753 \\
\text { 3. } 751 \\
\text { 3. } 748 \\
\text { 3. } 739\end{array}$ \\
\hline
\end{tabular}

TABLE 3.-Calculation of the dissociation constant of formic acid from electrometric titration of sodium formate with nitric acid reagent: experiment $2,25^{\circ} C$

[Millimoles of sodium formate $=4.965$, dissolved in $100 \mathrm{ml}$ of $0.05-m$ sodium chloride solution; ionic strength constant, $\left.\mu=0.0997 ;-\log f_{i}=0.114 ; E^{\circ \prime}=0.30606\right]$

\begin{tabular}{|c|c|c|c|c|c|c|c|}
\hline $\mathrm{HNO}_{3}$ & $E$ & $\left(E-E^{\circ \prime}\right) / k=\mathrm{pH}$ & $M_{\mathrm{H}}$ & HA & $A^{-}$ & $\log \left(M_{\mathrm{A}} / M_{\mathbf{H A}}\right)$ & $\mathrm{p} \boldsymbol{K}^{\prime}$ \\
\hline $\begin{array}{r}\text { Moles } \times 10^{3} \\
0.000 \\
.203 \\
.508 \\
.815 \\
1.016 \\
1.524 \\
2.029 \\
2.539 \\
3.050 \\
3.557 \\
4.066\end{array}$ & $\begin{array}{c}\text { Int. v } \\
0.7839 \\
.60272 \\
.57702 \\
.56304 \\
.55604 \\
.54208 \\
.53116 \\
.52140 \\
.51096 \\
.50106 \\
.48801\end{array}$ & $\begin{array}{l}8.081 \\
5.016 \\
4.582 \\
4.345 \\
4.227 \\
3.991 \\
3.806 \\
3.641 \\
3.465 \\
3.297 \\
3.077\end{array}$ & $\begin{array}{c}\text { Moles } \times 10^{3} \\
0.001 \\
.004 \\
.007 \\
.009 \\
.016 \\
.025 \\
.039 \\
.060 \\
.090 \\
.156\end{array}$ & $\begin{array}{r}\text { Moles } \times 10^{3} \\
0.202 \\
.504 \\
.808 \\
1.007 \\
1.508 \\
2.004 \\
2.500 \\
2.990 \\
3.467 \\
3.910\end{array}$ & $\begin{array}{c}\text { Moles } \times 10^{3} \\
4.763 \\
4.461 \\
4.157 \\
3.958 \\
3.457 \\
2.961 \\
2.465 \\
1.975 \\
1.498 \\
1.055\end{array}$ & $\begin{array}{r}1.363 \\
0.947 \\
.711 \\
.594 \\
.360 \\
.170 \\
-.006 \\
-.180 \\
-.365 \\
-.569\end{array}$ & $\begin{array}{l}\text { 3. } 767 \\
\text { 3. } 749 \\
\text { 3. } 748 \\
\text { 3. } 747 \\
\text { 3. } 745 \\
\text { 3. } 750 \\
\text { 3. } 761 \\
\text { 3. } 759 \\
\text { 3. } 776 \\
\text { 3. } 760\end{array}$ \\
\hline
\end{tabular}

TABLE 4.-Calculation of the dissociation constant of formic acid from electrometric titration of sodium formate with nitric acid reagent: experiment $3,25^{\circ} \mathrm{C}$

[Millimoles of sodium formate $=5.005$, dissolved in $200 \mathrm{ml}$ of $0.05-\mathrm{m}$ sodium chloride solution; $\mu$ at beginning $=0.0750, \mu$ at end $=0.0799 ; \mu$ (average) $\left.=0.0775 .-\log f_{i}=0.104 ; E^{\circ \prime}=0.30547\right]$

\begin{tabular}{|c|c|c|c|c|c|c|c|}
\hline $\mathrm{HNO}_{3}$ & $E$ & $\left(E-E^{\circ \prime}\right) / k=\mathrm{pH}$ & $M_{\mathrm{H}}$ & HA & $\mathrm{A}^{-}$ & $\log \left(M_{\mathrm{A}} / M_{\mathrm{HA}}\right)$ & $\mathrm{p} K^{\prime}$ \\
\hline $\begin{array}{r}\text { Moles } \times 10^{3} \\
0.000 \\
.200 \\
.508 \\
.811 \\
1.024 \\
1.521 \\
1.778 \\
2.030 \\
2.286 \\
2.540 \\
2.794 \\
3.049 \\
3.557 \\
4.066\end{array}$ & $\begin{array}{c}\text { Int. v } \\
0.7346 \\
.60347 \\
.57718 \\
.56345 \\
.55616 \\
.54272 \\
.53681 \\
.53144 \\
.52627 \\
.52124 \\
.51637 \\
.51138 \\
.50118 \\
.49012\end{array}$ & $\begin{array}{l}7.256 \\
5.039 \\
4.594 \\
4.362 \\
4.239 \\
4.012 \\
3.912 \\
3.821 \\
3.733 \\
3.648 \\
3.566 \\
3.482 \\
3.309 \\
3.122\end{array}$ & $\begin{array}{c}\text { Moles } \times 10^{3} \\
0.002 \\
.007 \\
.012 \\
.016 \\
.028 \\
.035 \\
.044 \\
.054 \\
.067 \\
.081 \\
.100 \\
.149 \\
.235\end{array}$ & $\begin{array}{r}\text { Moles } \times 10^{3} \\
0.198 \\
.501 \\
.799 \\
1.008 \\
1.493 \\
1.743 \\
1.986 \\
2.232 \\
2.473 \\
2.713 \\
2.949 \\
3.408 \\
3.831\end{array}$ & $\begin{array}{c}\text { Moles } \times 10^{3} \\
4.807 \\
4.504 \\
4.206 \\
3.997 \\
3.512 \\
\text { 3. } 262 \\
\text { 3. } 019 \\
2.773 \\
2.532 \\
2.292 \\
2.056 \\
1.597 \\
1.174\end{array}$ & $\begin{array}{r}1.385 \\
0.954 \\
.721 \\
.598 \\
.371 \\
.272 \\
.182 \\
.094 \\
.010 \\
-.073 \\
-.157 \\
-.329 \\
-.514\end{array}$ & $\begin{array}{l}3.758 \\
3.744 \\
3.745 \\
3.745 \\
3.745 \\
3.744 \\
3.743 \\
3.743 \\
3.742 \\
3.743 \\
3.743 \\
3.742 \\
3.740\end{array}$ \\
\hline
\end{tabular}


TABLE 5.-Calculation of the dissociation constant of acetic acid from electrometric titration of sodium acetate with nitric acid reagent: experiment $4,25^{\circ} \mathrm{C}$

[Millimoles of sodium acetate $=4.984$, dissolved in $100 \mathrm{ml}$ of $0.05-\mathrm{m}$ sodium chloride solution; ionic strength. constant, $\left.\mu=0.0998 ;-\log f_{i}=0.114 ; E^{\circ \prime}=0.30606\right]$

\begin{tabular}{|c|c|c|c|c|c|c|c|}
\hline $\mathrm{HNO}_{3}$ & $E$ & $\left(E-E^{\circ \prime}\right) / k=\mathrm{pH}$ & $M_{\mathrm{H}}$ & $\mathrm{HA}$ & $A-$ & $\log \left(M_{\mathrm{A}} / M_{\mathrm{HA}}\right)$ & $\mathrm{p} K^{\prime}$ \\
\hline $\begin{array}{r}\text { Moles } \times 10^{3} \\
0.000\end{array}$ & $\begin{array}{l}\text { Int. } v \\
0.7641\end{array}$ & 7.745 & Moles $\times 10^{3}$ & Moles $\times 10^{3}$ & Moles $\times 10^{3}$ & & \\
\hline .174 & .66617 & 6. 089 & 0.00 & 0.174 & 4.810 & 1.442 & 4.761 \\
\hline .477 & .63860 & 5. 623 & .000 & 477 & 4. 507 & 0.975 & 4.762 \\
\hline .787 & .62385 & 5. 373 & .001 & 786 & 4. 198 & .728 & 4.759 \\
\hline .982 & .61676 & 5. 254 & .001 & .981 & 4.003 & .611 & 4.757 \\
\hline 1.489 & .60261 & 5. 014 & .002 & 1.487 & 3.497 & .371 & 4.757 \\
\hline 1.994 & .59102 & 4.818 & .003 & 1. 991 & 2.993 & .177 & 4.755 \\
\hline 2.505 & .58034 & 4. 638 & .004 & 2. 501 & 2.483 & -.003 & 4.755 \\
\hline 3.013 & .56970 & 4.458 & .006 & 3. 007 & 1.977 & -.182 & 4. 754 \\
\hline 3.521 & .55818 & 4. 263 & .009 & 3. 512 & 1.472 & -.378 & 4.755 \\
\hline 4.037 & .54387 & 4. 021 & .015 & 4. 022 & 0.962 & -.621 & 4. 756 \\
\hline 4.133 & .54058 & 3. 966 & .021 & 4. 112 & .872 & -.673 & 4.753 \\
\hline 4. 239 & .53675 & 3. 901 & .024 & 4. 215 & .769 & -.739 & 4.754 \\
\hline 4.343 & .53261 & 3. 831 & .029 & 4. 314 & .670 & -.809 & 4.754 \\
\hline 4.444 & .52799 & 3.753 & .034 & 4. 410 & .574 & -.885 & 4. 752 \\
\hline 4. 537 & .52313 & 3.670 & .041 & 4. 496 & .488 & -.965 & 4. 749 \\
\hline 4.649 & .51649 & 3. 558 & .054 & 4. 595 & .389 & -1.072 & 4. 744 \\
\hline 4.746 & .50994 & 3.447 & .070 & 4. 676 & .308 & -1.181 & 4.742 \\
\hline 4.839 & .50255 & 3. 322 & .094 & 4. 745 & .239 & -1.298 & 4. 734 \\
\hline 4.940 & .49340 & 3.168 & .134 & 4. 806 & .178 & -1.431 & 4. 713 \\
\hline
\end{tabular}

TABLE 6.-Calculation of the dissociation constant of acetic acid from electrometric titration of sodium acetate with nitric acid reagent: experiment $5,25^{\circ} \mathrm{C}$

[Millimoles of sodium acetate $=4.938$, dissolved in $100 \mathrm{ml}$ of $0.05-m$ sodium chloride solution; ionic strength constant, $\left.\mu=0.0994 ;-\log f_{i}=0.114 ; \mathrm{E}^{\circ \prime}=0.30606\right]$

\begin{tabular}{|c|c|c|c|c|c|c|c|}
\hline $\mathrm{HNO}_{3}$ & $E$ & $\left(E-E^{\circ \prime}\right) / k=\mathrm{pH}$ & $M_{\mathrm{H}}$ & HA & $A-$ & $\log \left(M_{\mathrm{A}} / M_{\mathrm{HA}}\right)$ & $\mathrm{p} K^{\prime}$ \\
\hline $\begin{array}{c}\text { Moles } \times 10^{3} \\
0.000 \\
.206 \\
.511 \\
.816 \\
1.020 \\
1.526 \\
2.034 \\
2.543 \\
3.051 \\
3.561 \\
4.069 \\
4.272 \\
4.476 \\
4.677\end{array}$ & $\begin{array}{c}\text { Int. } v \\
0.7590 \\
.66154 \\
.63634 \\
.62251 \\
.61536 \\
.60155 \\
.58994 \\
.57920 \\
.56840 \\
.55653 \\
.54153 \\
.53424 \\
.52481 \\
.51206\end{array}$ & $\begin{array}{l}7.659 \\
6.011 \\
5.585 \\
5.351 \\
5.230 \\
4.996 \\
4.800 \\
4.618 \\
4.436 \\
4.235 \\
3.982 \\
3.858 \\
3.699 \\
3.483\end{array}$ & $\begin{array}{c}\text { Moles } \times 10^{3} \\
0.000 \\
.000 \\
.001 \\
.001 \\
.002 \\
.003 \\
.004 \\
.006 \\
.009 \\
.017 \\
.023 \\
.039 \\
.064\end{array}$ & $\begin{array}{r}\text { Moles } \times 10^{3} \\
0.206 \\
.511 \\
.815 \\
1.019 \\
1.524 \\
2.031 \\
2.539 \\
3.045 \\
3.552 \\
4.052 \\
4.249 \\
4.437 \\
4.613\end{array}$ & \begin{tabular}{|c|} 
Moles $\times 10^{3}$ \\
4.732 \\
4.427 \\
4.123 \\
3.919 \\
3.414 \\
2.907 \\
2.399 \\
1.893 \\
1.386 \\
0.886 \\
.689 \\
.501 \\
.325
\end{tabular} & $\begin{array}{r}1.361 \\
0.938 \\
.704 \\
.585 \\
.350 \\
.156 \\
-.025 \\
-.206 \\
-.409 \\
-.660 \\
-.790 \\
-.947 \\
-1.152\end{array}$ & $\begin{array}{l}4.764 \\
4.761 \\
4.761 \\
4.759 \\
4.760 \\
4.758 \\
4.757 \\
4.756 \\
4.758 \\
4.756 \\
4.762 \\
4.760 \\
4.749\end{array}$ \\
\hline
\end{tabular}

TABLE 7.-Calculation of the dissociation constant of acetic acid from electrometric titration of sodium acetate with nitric acid reagent: experiment $6,25^{\circ} \mathrm{C}$

[Millimoles of sodium acetate $=4.928$, dissolved in $200 \mathrm{ml}$ of $0.05-\mathrm{m}$ sodium chloride solution; $\mu$ at beginning $=0.075, \mu$ at end $=0.079, \mu$ (average) $\left.=0.077 ;-\log f_{i}=0.104 ; E^{\circ \prime}=0.30547\right]$

\begin{tabular}{|c|c|c|c|c|c|c|c|}
\hline $\mathrm{HNO}_{3}$ & $E$ & $\left(E-E^{\circ \prime}\right) / k=\mathrm{pH}$ & $M_{\mathrm{H}}$ & $\mathrm{HA}$ & $A-$ & $\log \left(M_{\mathrm{A}} / M_{\mathrm{HA}}\right)$ & $\mathrm{p} K^{\prime}$ \\
\hline $\begin{array}{c}\text { Moles } \times 10^{3} \\
0.000\end{array}$ & Int. $v$ & & Moles $\times 10^{3}$ & Moles $\times 10^{3}$ & Moles $\times 10^{3}$ & & \\
\hline $\begin{array}{r}0.000 \\
.051\end{array}$ & $\begin{array}{l}0.7553 \\
.69645\end{array}$ & $\begin{array}{l}7.606 \\
6.611\end{array}$ & 0.000 & 0.051 & 4.877 & 1. 971 & 4.744 \\
\hline .206 & .66073 & 6.007 & .000 & .206 & 4. 722 & 1. 360 & 4. 751 \\
\hline .512 & .63606 & 5.590 & .001 & .511 & 4. 417 & 0.937 & 4. 757 \\
\hline .821 & .62205 & 5.353 & .001 & .820 & 4. 108 & .700 & 4. 757 \\
\hline 1.021 & .61554 & 5.243 & .002 & 1.019 & 3. 909 & .584 & 4. 763 \\
\hline 1. 534 & .60153 & 5.006 & .003 & 1. 531 & 3. 397 & .346 & 4. 764 \\
\hline 2.044 & .58999 & 4. 811 & .005 & 2. 039 & 2. 889 & .151 & 4. 764 \\
\hline 2.560 & .57929 & 4. 630 & .007 & 2. 553 & 2. 375 & -.031 & 4. 765 \\
\hline 3.069 & .56870 & 4. 451 & .011 & 3.058 & 1.870 & -.214 & 4. 769 \\
\hline 3.582 & .55676 & 4. 249 & .016 & 3. 566 & 1. 362 & -.418 & 4. 771 \\
\hline 4.097 & .54197 & 3.999 & .030 & 4. 067 & .861 & -.674 & 4.777 \\
\hline
\end{tabular}


In the fourth column of each table, $M_{\mathrm{H}}$ represents the number of moles of hydrogen ion in $v \mathrm{ml}$ of solution, where $v$ is the total volume of solution in the titration cell. Thus $M_{\mathrm{H}} \approx m_{\mathrm{H}} v / 1000$, where $m_{\mathrm{H}}$ is the molality of hydrogen ion computed from the $\mathrm{pH}$ value:

$$
-\log m_{\mathrm{H}}=\mathrm{pH}+\log f_{1} \text {. }
$$

The number of moles of weak acid, HA, given in the fifth column of each table, was obtained by subtracting $M_{\mathrm{H}}$ from the amount of nitric acid listed in the first column. The values of $\mathrm{A}^{-}$(sixth column) are the differences between the amount of sodium salt used (given at the head of each table) and the amounts of HA.

The average $\mathrm{p} K^{\prime}$ value for each experiment is given in table 8 . The last two measurements of experiments 1 and 4 , when more than 95 percent of the salt had been neutralized, have not been included in the average. The averages of all the $\mathrm{p} K^{\prime}$ values derived from these experiments agree very well (0.001 unit) with the best values of $\mathrm{p} \bar{K}$ for these two acids given in the literature $[10,11]$.

TABLE 8.-Summary of $\mathrm{p} K^{\prime}, \mathrm{p} K$, and $K$ for formic acid and acetic acid at $25^{\circ} C$

\begin{tabular}{|c|c|c|c|c|c|}
\hline Experiment number & $\operatorname{avg} \mathrm{p} K^{\prime}$ & $\mu$ & $\mathrm{p} K^{\prime}-\mathrm{p} K$ & $\mathrm{p} K$ & $K \times 10^{5}$ \\
\hline \multicolumn{6}{|c|}{ FORMIC ACID } \\
\hline $\begin{array}{l}1 \\
2 \\
3\end{array}$ & $\begin{array}{r}\text { 8 } 3.751 \\
3.756 \\
3.744\end{array}$ & $\begin{array}{l}0.1 \\
.1 \\
.078\end{array}$ & $\begin{array}{l}0.01 \\
.009 \\
.007\end{array}$ & $\begin{array}{r}\text { a } 3.741 \\
3.747 \\
3.737\end{array}$ & $\begin{aligned} & \\
& 18.2 \\
& 17.9 \\
& 18.3\end{aligned}$ \\
\hline Mean $\left(25^{\circ} \mathrm{C}\right)$ & & & & 3. 742 & 18.1 \\
\hline \multicolumn{6}{|c|}{ ACETIC ACID } \\
\hline \multirow{2}{*}{ Mean $\left(25^{\circ} \mathrm{C}\right)$} & $\begin{array}{l}4.753 \\
4.758 \\
4.762\end{array}$ & $\begin{array}{l}0.1 \\
.1 \\
.077\end{array}$ & $\begin{array}{l}0.005 \\
.005 \\
.003\end{array}$ & $\begin{array}{l}4.748 \\
4.753 \\
4.759\end{array}$ & $\begin{array}{l}1.79 \\
1.77 \\
1.74\end{array}$ \\
\hline & & & & 4. 754 & 1. 77 \\
\hline
\end{tabular}

at $30^{\circ} \mathrm{C}$.

Since $p K^{\prime}$ for many monobasic acids at an ionic strength of 0.1 differs but little from the value at zero ionic strength, it is probably unnecessary for practical work to make the large number of measurements requisite to an unambiguous extrapolation. For a check on the accuracy of the method, however, $\mathrm{p} K$ was computed from $\mathrm{p} K^{\prime}$ by the application of extrapolation corrections taken from the careful measurements of the dissociation constant of formic acid by Harned and Embree [10] and of the dissociation constant of acetic acid by Harned and Ehlers [11]. These corrections, the amounts to be subtracted from $\mathrm{p} K^{\prime}$, are given in the fourth column of table 8, and the $\mathrm{p} K$ values are listed in the fifth column. The dissociation constant, $K$, is listed in the sixth column. Harned and Embree found 3.752 and 3.753 for the $\mathrm{p} K$ values of formic acid at $25^{\circ}$ and $30^{\circ} \mathrm{C}$, respectively, and Harned and Ehlers have given 4.756 for the $\mathrm{p} K$ of acetic acid at $25^{\circ} \mathrm{C}$.

It is evident that the electrometric titration, modified as described in this paper, may have consdiderable usefulness as a practical means of determining dissociation constants of weak monobasic acids and 
$\mathrm{pH}$ values of buffer solutions with an accuracy of 0.01 to 0.02 unit. By substitution of a glass or quinhydrone electrode, the application of the method can be extended to many systems in which the hydrogen electrode cannot be used.

Titration curves and dissociation constants of weak polybasic acids at constant ionic strength can be obtained by modifications of the method described here. To obtain data for the second, third, etc., groups, the corresponding salt is titrated in sodium chloride solution with nitric acid solution to which has been added sodium chloride and sufficient potassium nitrate to compensate for the decrease in ionic strength during the titration. As an alternate procedure, a disodium salt can be titrated with a solution of acid sulfate and sodium chloride which contains enough neutral salt to compensate for the decrease in ionic strength and to maintain a constant concentration of bivalent ions, e. g., sulfate. The $\mathrm{pH}$ values in the range governed by the first dissociation constant are then obtained, as described in this paper, by the titration of the acid salt of the weak acid with nitric acid reagent. The determination of the concentration and dissociation constant of each acid group in a mixture [14] is improved by use of this procedure.

The titration method as outlined is not well adapted for use over a wide range of temperatures. It cannot conveniently furnish the accurate data over a wide range of ionic strengths which are required to determine $a_{i}$ and $\beta$ parameters. Wherever it can be used, however, it represents a considerable improvement over a pH assembly with liquid junction.

Because of these limitations, the electrometric titration method is unsuitable for the precise determination of dissociation constants and $\mathrm{pH}$ values of buffer standards. When an accuracy within 0.003 unit is desired, the emf method described in earlier papers from this Bureau $[6,7,12]$ should be employed. The improved titration should be regarded rather as a rapid method of establishing dissociation constants and practical buffer standards for $\mathrm{pH}$ control where an uncertainty of 0.02 unit is permissible.

\section{REFERENCES}

[1] R. G. Bates, W. J. Hamer, G. G. Manov, and S. F. Acree, J. Research NBS 29, 183 (1942) RP1495.

[2] W. J. Hamer, Trans. Electrochem. Soc. 72, 45 (1937).

[3] C. S. Cragoe, J. Research NBS 86,495 (1941) RP1393.

[4] H. T. Wensel, J. Research NBS 2\%, 375 (1939) RP1189.

[5] E. Hückel, Physik. Z. 26, 93 (1925).

[6] W. J. Hamer, J. O. Burton, and S. F. Acree, J. Research NBS 24, 269 (1940) RP1284.

[7] W. J. Hamer and S. F. Acree, J. Research NBS 23, 647 (1939) RP1261.

[8] M. R. Meacham, J. J. Hopfield, and S. F. Acree, J. Bact. 5, 491 (1920).

[9] R. R. Mellon, S. F. Acree, P. M. Avery, and E. A. Slagle, J. Infectious Diseases 29, 1 (1921).

[10] H. S. Harned and N. D. Embree, J. Am. Chem. Soc. 56, 1042 (1934).

[11] H. S. Harned and R. W. Ehlers, J. Am. Chem. Soc. 54, 1350 (1932).

[12] R. G. Bates and S. F. Acree, J. Research NBS 30, 129 (1943) RP1524.

[13] J. O. Burton, W. J. Hamer, and S. F. Acree, J. Research NBS 16, 575 (1936) RP895.

[14] J. O. Burton and S. F. Acree, J. Research NBS 16, 525 (1936) RP889.

Washington, March 1, 1943. 